\title{
SASSEN, SASKIA. SOCIOLOGIA \\ Da Globalização. Porto Alegre. \\ EDITORA ARTMED. 2010.
}

\section{POR UMA SOCIOlOGIA DA GLOBALIZAÇÃo}

Gisele Maria Ribeiro de Almeida*

Lidiane M. Maciel**

Saskia Sassen é uma socióloga holandesa, atualmente professora da Universidade de Chicago, cujos trabalhos buscam analisar a dinâmica que reproduz a economia global e suas repercussões. Escreveu cerca de dez livros sobre essa temática, mas suas obras quase não foram traduzidas e editadas no Brasil. Exceção é o livro "As cidades na economia mundial" que foi lançado pela Studio Nobel em 1998 e agora em 2010, o seu penúltimo livro chamado "Sociologia da Globalização" foi publicado pela editora Artmed.

Segundo a autora, o livro "Sociologia da Globalização" foi "encomendado" por Jeffrey Alexander e objetiva contribuir para a compreensão do fenômeno da globalização e sua complexidade. Para dar conta desta tarefa, apresenta uma agenda de pesquisa e propõe caminhos analíticos para os estudos acerca da

\footnotetext{
* Doutoranda em Sociologia pelo Instituto de Filosofia e Ciências Humanas - Unicamp.

** Mestranda em Sociologia pelo Instituto de Filosofia e Ciências Humanas - Unicamp.
} 
globalização, particularmente no que tange ao campo disciplinar da sociologia.

O livro é de alguma forma uma compilação das ideias apresentadas em outras obras da autora, assim alguns capítulos podem parecer redundantes ao leitor que conhece sua obra. No entanto, a revisão de seus argumentos traz contribuições importantes para um olhar sociológico atento a certos fenômenos contemporâneos que na maior parte dos casos se apresentam como efêmeros demais para serem captados pelo conhecimento científico. O livro de Sassen se propõe a enfrentar esse desafio e sugere elementos a serem considerados por uma "sociologia da globalização".

Além da introdução, bastante clara aos seus propósitos, a obra tem sete capítulos. No capítulo intitulado "Elementos para uma sociologia da globalização", que abre a discussão, a autora apresenta críticas aos estudos sobre o global, seu argumento principal é que via de regra tais estudos incorporam noções equivocadas de lugar e de escala, por não reconhecer que a realidade da mundialização erigiu novos escalonamentos superpostos, de forma que falar em subnacional ou supranacional de maneira estanque não faz mais o menor sentido.

Portanto, para considerar a globalização de um ponto vista crítico, a autora insiste na importância de se considerar o papel de esferas tipicamente nacionais na formação do sistema global. As cidades globais são para Sassen a melhor evidência de que as escalas não têm mais hierarquias rígidas, isso porque estas cidades oferecem condições locais para o funcionamento de instituições de atuação e alcance global, como os mercados de capitais.

Assim, para a autora, no âmbito das Ciências Sociais, não reconhecer que o modelo das hierarquias escalares implodiu pode ser um entrave analítico nas pesquisas sobre a globalização, e uma das evidências deste problema seria demonstrada pela falta de uma postura mais crítica, capaz de historicizar a escala do nacional, e que normalmente tem resultado em uma percepção rígida desta dimensão e impedido uma compreensão adequada 
deste processo global nas discussões elaboradas até o momento pela área disciplinar.

Avançando nesta perspectiva, Sassen discute em seguida o "lugar" do Estado no cenário da globalização e seu argumento central questiona o papel passivo que esse teria assumido na nova ordem mundializada. Ao contrário, para ela o Estado-Nação tem uma posição estratégica na globalização sendo, portanto, essencial que uma sociologia da globalização supere a visão analítica usual, que "enxerga" apenas o enfraquecimento deste frente aos processos globais.

O papel do Estado para a autora é primordial porque cabe a ele regulamentar a desregulamentar processos e prerrogativas. Desta forma, há um reposicionamento do Estado no campo de poder e a reconfiguração de sua atuação. Com isso, Sassen não ignora o funcionamento de uma geografia do poder, a força dos Estados não é homogênea, de forma que a orientação e a definição destas regulamentações e desregulamentações cabem aos mais poderosos.

As consequências disso para uma sociologia da globalização é que pela dinâmica do capitalismo global o dualismo entre Estado e Mercado deixa de existir, dado que as exigências do mercado são incorporadas pela institucionalidade estatal, temos então, como cita a autora "a formação de uma nova ordem institucional privada ligada a economia global" (p. 32)

Para Sassen, essa conjuntura econômica e institucional está localizada nas cidades globais, que se constituem em lugares estratégicos para a reprodução da economia global, o que significa a exigência de uma materialidade, que está sediada nesses espaços nacionais específicos. É importante frisar que isso ocorre porque a reprodução do capitalismo global é complexa e essa complexidade repercute em demandas materiais e locais dentro de uma "geografia estratégica" que engendra as cidades globais. Estas cidades revelam tanto o processo de desnacionalização quanto o enraizamento local e material da globalização, voltando ao seu argumento de que a globalização realiza uma ruptura com a usual hierarquia de escala. 
Por isso, para a autora, as cidades globais e a rede que elas formam são pontos vitais na agenda de pesquisa de uma "sociologia da globalização"; isso porque é através das cidades globais e da rede que as conectam que a economia global é administrada e, portanto reproduzida. Segundo Sassen, as grandes cidades reconfiguram a nova ordem social e funcionam como uma "estrutura complexa" capaz de alinhavar os processos atualmente denominados de transfronteiriços. Assim, ao discutir a cidade global, Saskia Sassen propõe a recuperação do "lugar" e suas "práticas sociais" pela sociologia da globalização.

O capítulo seguinte "A criação de migrações internacionais", aborda as migrações internacionais como parte da dinâmica social desenvolvida nas cidades globais. A mão de obra imigrante é uma categoria transnacional importante na vida cotidiana da cidade global; um local no qual os imperativos globais que a atingem, acabam por transformá-la em "uma zona de fronteira para um novo tipo de relação" (p. 107).

As migrações internacionais já eram objeto de reflexão da autora em livro anterior. Em "The Mobility of Labor and Capital: a Study in International Investment and Labor Flow"1 editado pela Universidade de Cambridge em 1988, Sassen demonstrou o equívoco das análises voltadas à compreensão do fenômeno migratório, que se mantêm limitadas aos condicionantes da origem (como superpopulação, pobreza e estagnação econômica) e por isso pensam o fenômeno das migrações internacionais por uma ótica nacional. Sua proposta é que a compreensão destes fluxos exige que se contemplem fatores internacionais. Ao mesmo tempo em que Sassen reconhece que estes fatores de expulsão possam gerar pressões migratórias, isso não levaria à migração em larga escala necessariamente. É preciso, como aponta, que hajam outros efeitos catalizadores da migração. No caso, estes efeitos resultam na formação de vínculos entre os países, como

${ }^{1}$ Há uma tradução para o espanho. SASSEN, Saskia. La movilidad del trabajo y del capital. Madri: Ministério de Trabajo y Seguridad Social, 1993. 
os investimentos estrangeiros e a presença de empresas multinacionais.

Opondo-se a uma visão econômica e unilateral explicativa do fenômeno, Sassen reconhece o peso das representações ideológicas e os impactos para a subjetividade dos imigrantes neste cenário ${ }^{2}$, sejam elas criadas pelas conexões coloniais e neocoloniais, ou pela exposição diária a propaganda do mundo global que atingem diversas populações nos mais longínquos recantos. Ou seja, não necessariamente são os países mais pobres que tem ou terão emigrantes, como seria pela ótica teórica da "atração versus repulsão", mas sim aqueles nos quais houve investimentos estrangeiros e nos quais a cultura ocidental teve mais proeminência, ou seja, a questão é "como a globalização encurta a distância material e subjetiva entre o país de origem e destino" (p. 114).

Neste livro, Sassen recoloca suas críticas em relação às abordagens clássicas que supervalorizam os fatores de expulsão na origem. Seu objetivo é demonstrar como e quando as migrações contemporâneas são influenciadas particularmente pela globalização, enfim quais os fluxos que realmente poderiam ser vistos como estimulados por ela, dado que as migrações internacionais já existiam antes da emergência do capitalismo global. Além da importância da variável "subjetividade do imigrante" anteriormente mencionada, a autora reconhece a singularidade que pode se manifestar em cada fluxo em particular; no entanto, metodologicamente sua sugestão é buscar as tendências gerais, capazes de revelar os efeitos da globalização econômica e cultural sobre estes deslocamentos humanos. Em outras palavras, a autora menciona por exemplo que há sem dúvida o peso da herança colonial em vários processos migratórios

2 "Guests and aliens" é um livro de Sassen que saiu pela editora New Press de Nova York em 1999. Nesta obra, a autora apresenta um panorama histórico das migrações internacionais na Europa nos últimos dois séculos. Seu objetivo encontrar nesta reflexão elementos que podem municiar o debate norte-americano sobre o assunto. 
destinados à Europa, mas sua ênfase está no reconhecimento das "novas" dinâmicas que conectam esses locais de origem e destino dos migrantes. Os elos de ligação podem de fato ser anteriores a esse processo, mas seu argumento é que diante da globalização acabam por ser reconfigurados ou mesmo restabelecidos. Aponta também a possibilidade da instauração de ligações totalmente novas, engendradas no interior da dinâmica global. A tarefa então é identificar como e porque isso acontece, em ambos os casos.

Nessa nova etapa migratória, o agenciamento e a exportação organizada de trabalhadores ganha importância na medida em que sustenta a reprodução do capital global, pela formação de uma classe de trabalhadores internacionais mal remunerados e que representa uma importante fonte de divisas para muitos países, geradas pelas remessas direcionadas as famílias que ficam. As redes que se formam seja no recrutamento legal de trabalhadores, seja no tráfico de pessoas, criam novas dinâmicas fundamentais porque viabilizam que a migração internacional se torne uma possibilidade real para muitos indivíduos que outrora não a vislumbrava como alternativa de sobrevivência. A "criação" das migrações internacionais estabeleceu, para além das velhas e novas conexões econômicas, novas formas de conexões e, sobretudo de dependência entre os países.

Assim, caminhando para última parte do livro, Sassen, apresenta a problemática das classes globais, que em alguma medida toca a temática das migrações internacionais. A autora buscou compreender a emergência destas classes pelo referencial sociológico e, na sua avaliação, o conceito de classes sociais não está perdendo significado heurístico. Ao contrário, pode estabelecer caminhos analíticos profícuos na discussão de como práticas e culturas específicas assumem relevância nos mecanismos de funcionamento da estrutura econômica mundializada.

Para a autora as classes ainda são entendidas enquanto forma de agregar grupos sociais, e devem ser pensadas a partir de critérios objetivos e subjetivos. Sassen identificou três classes globais: as elites transnacionais, as redes transnacionais formadas 
por autoridades governamentais e a classe global de trabalhadores desfavorecidos e ativistas engajados em organizações da sociedade civil global. A hipótese da autora é que apesar da aparência, tais classes não são cosmopolitas, todas elas de uma forma ou de outra estão localizadas e informadas por contextos particulares, pelos governos nacionais ou ainda por microestruturas presentes no cotidiano. Em resumo, estas classes são reconhecidas como forças sociais emergentes com capacidade de influenciar a política governamental nacional. Mais uma vez, as questões que envolvem as escalas cruzadas e o enraizamento local são retomadas como inerentes à reprodução do capital global.

Frente às classes globais e sua posição intermediária entre o local e o global, Sassen também vislumbra a ação dos atores locais na política global, e dedica a penúltima parte do livro a esses atores, ao refletir sobre a presença deles nas esferas públicas nacionais e global. Apesar do aparente paradoxo, para a socióloga isso ocorre em função da maior permeabilidade da arena política internacional, que teria sido resultado dos efeitos da própria globalização e das novas Tecnologias de Informação e Comunicação (TICs).

A infraestrutura criada pelo capitalismo global deixa de funcionar apenas servindo à reprodução desta ordem global, para permitir que aflorem atores e lutas engajados em questioná-la. Estes "atores globais" que emergem estão situados em localidades específicas, mas compõem redes sociais e esferas públicas de âmbito mundial. Como resultado, estes atores que são locais pelas lutas que travam e pelo espaço que os circundam acabam por integrar lutas e espaços transfronteiriços. Há um processo semelhante à constituição das cidades globais e da rede por elas criadas, no entanto cabe distinguir, de acordo com Sassen, que as novas práticas e técnicas políticas engendradas pelas TICs viabilizam a atuação de áreas periféricas, processo que pode impactar a geografia do poder estabelecida. A política local que a priori estaria enfraquecida no contexto da globalização pode, diante deste cenário, ser potencializada, assim como significados e imaginários globais podem aí se difundir e daí emergir. 
O último capítulo dedica-se a "fechar" a discussão, pois apresenta uma reflexão sobre como estas "novas" formações globais se articulam aos desafios de uma agenda de pesquisa relativa ao campo da sociologia em particular, e que é afinal de contas a preocupação que norteou a obra. O cerne, a partir da qual se desenrola a argumentação da autora, é a noção de fronteira. Das fronteiras nacionais a contextualizadas, nas quais as demarcações geográficas simplificadoras dão lugar a "outras instituições e envolvem mais locais do que sugerem as representações comuns" (p. 179). Para Sassen, os processos de globalização foram responsáveis por criar novas fronteiras, redefini-las ou resignificá-las. Se até então o nacionalismo metodológico foi norteador das análises sobre geopolítica nos últimos séculos, a nova realidade impõe reformulações, na medida em que a noção de fronteira perde sua singularidade restrita ao Estado-Nação para abarcar novas formações, nas quais as fronteiras podem ser eliminadas como no caso do mercado de capitais, fortalecidas como no maior controle do fluxo de pessoas, ou ainda ampliadas como se verifica nos tratados e instituições internacionais.

Apreender os espaços virtuais e suas potencialidades enquanto práticas e culturas recolocam os desafios para o manejo de noções como fronteira, escala e lugar, ao mesmo tempo em que neste arranjo se define o objeto de uma sociologia de espaços digitais globais que colocam novos atores sociais na arena política da globalização.

Portanto, é trazendo à baila esse caleidoscópio que se forma pelo entrelaçamento destas complexas questões é que Sassen propõe uma agenda de pesquisa para uma sociologia da globalização. As temáticas por ela selecionadas foram gestadas pela dinâmica global desenhada nas últimas décadas. A contribuição teórica da autora para uma sociologia da globalização propõe uma leitura revisitada dos aspectos que ao seu ver compõem os desafios analíticos atuais como, por exemplo, a necessidade de rever a noção de hierarquia bem como do relacionamento que se estabelece entre as esferas hierárquicas 
presentes. A recuperação do local e do nacional nas análises sobre o global situa-se como a dimensão que melhor exemplifica a proposta apresentada por Saskia Sassen neste livro, pois a partir deste novo entendimento do global é que para ela se revelam as perspectivas analíticas que podem de fato viabilizar um entendimento do fenômeno em questão. 